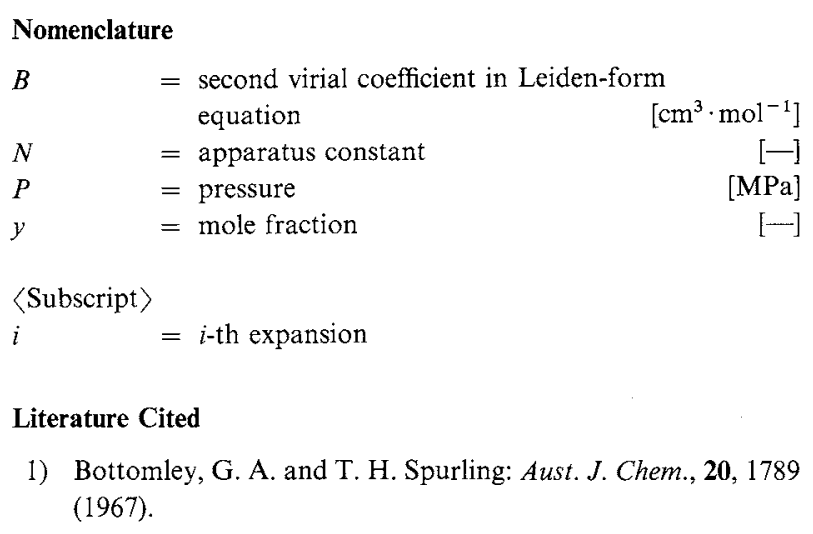

2) Fox, O. R., J. Morcillo and A. Mendez: An. R. Soc. Esp. Fis. Quim., 17B, 23 (1954).

3) Katayama, T., K. Ohgaki and H. Ohmori: J. Chem. Eng. Japan, 13, 257 (1980).

4) Kell, G. S. and G. E. McLaurin: J. Chem. Phys., 51, 4345 (1969).

5) Kudchadker, A. P. and P. T. Eubank: J. Chem. Eng. Data, 15, 7 (1970).

6) Newton, R. H. and B. F. Dodge: J. Am. Chem. Soc., 55, 4747 (1933).

7) Ohgaki, K., Y. Nakamura, H. Ariyasu and T. Katayama: $J$. Chem. Eng. Japan, 15, 85 (1982).

8) Ohgaki, K., T. Nakatani, T. Saito and T. Katayama: J. Chem. Eng. Japan, 15, 91 (1982).

\title{
BEHAVIOR OF POLYVINYL ALCOHOL ADDED AS A BINDER TO CLAYEY PARTICLES IN KNEADING AND DRYING OPERATIONS
}

HIDEHARU HIROSUE

Government Industrial Research Institute, Kyushu, Tosu 841

Key Words: Drying, Kneading, Polyvinyl Alcohol, Fine Clayey Particle, Adsorption, Critical Moisture

Content, Transferred Amount

The author has been trying to reuse wasted fine clayey particles as carriers for pesticides by means of spray drying and other operations. ${ }^{5)}$ In these operations, polyvinyl alcohol (PVA) was added as a binder to the clayey particles in order to increase the strength of the agglomerates in the dry state. ${ }^{3)}$ However, as the behavior of PVA has not been exactly determined in kneading and drying operations, ${ }^{1}{ }^{1}$ it is considered in this paper.

\section{Experimental}

Sample Talc having a median diameter of $7.9 \mu \mathrm{m}$ was used as a sort of fine clayey particles. PVA having a degree of polymerization of about 500 and a degree of saponification of 86.5 to 89.0 was used as a binder. Adsorption of PVA on talc particles The adsorption isotherm of PVA on talc was measured to find a plateau adsorption value. The adsorption equilibrium was confirmed to be roughly reached within $24 \mathrm{~h}$. The initial and equilibrium concentrations of PVA in the solution were determined on the basis of the method developed by Zwick. ${ }^{6)}$

Received July 25, 1983. Correspondence concerning this article should be addressed to H. Hirosue.
Drying characteristic of moist agglomerate and behavior of PVA in drying operation In order to make moist cylindrical agglomerates, distilled water or an aqueous solution of PVA was added to dried clayey particles. The wetted clayey particles were then kneaded and formed into cylindrical shapes $2 \mathrm{~cm} \phi$ in diameter and 5 to $6 \mathrm{~cm}$ in length by means of an auger machine, the inside of which was kept in vacuum.

In measuring the drying rate on a moist cylindrical agglomerate without PVA, the side and one end of the agglomerate were wrapped two or three times with a polyethylene sheet $0.03 \mathrm{~mm}$ in thickness. The polyethylene sheet on the side was tightened with rubber bands in order to compel liquid flow in the axial direction. The drying characteristic of the agglomerate was measured by using a drying oven kept at $333 \pm 2 \mathrm{~K}$.

After the moist agglomerate containing PVA was completely dried by the same procedure as above, the agglomerate was cut at 0.5 or $1.0 \mathrm{~cm}$ intervals from the drying surface. Then the dissolved amount of PVA was measured for every cut sample to determine the longitudinal distribution of dissolved PVA. 


\section{Experimental Results and Discussion}

Adsorption of PVA on talc particles The adsorption isotherms of PVA on talc particles at 298 and $313 \mathrm{~K}$ are indicated in Fig. 1. This figure shows that the influence of temperature on the amount of adsorption is very small ${ }^{4)}$ and the adsorption isotherms are of the Langmuir type. ${ }^{2)}$ The following was obtained as the Langmuir equation and is compared with experimental results in Fig. 1.

$$
C / \Gamma=219 C+0.005
$$

The plateau adsorption value, $C_{e}$, was roughly equal to $4.6 \times 10^{-3} \mathrm{~kg}$ PVA $/ \mathrm{kg}$ talc $(0.46 \%)$.

Drying characteristic of moist agglomerate and behavior of PVA in drying operation The drying rate of a moist agglomerate without PVA is given in Fig. 2. From this figure, the critical moisture content, $w_{c}$, is found to be 0.21 . Figure 3 presents the longitudinal distributions of PVA dissolved from the agglomerates. The dissolution experiments were performed one or five times. It is recognized from the figure that when $C_{i}$ is equal to $0.475 \%$, the distribution and amount of dissolved PVA in the longitudinal direction are very small because most of the PVA is adsorbed on the talc particles as described before and movement is restricted. It is also evident that the dissolved amount of PVA in the vicinity of the drying surface is extremely high in comparison with that in the interior of the agglomerate in the case of $C_{i}=$ $0.94 \%$.

The amount of PVA brought to the drying surface can be approximately estimated by the following method. When it is assumed that the moisture moves as liquid from an initial moisture content, $w_{i}$, to a critical moisture content, $w_{c}$, obtained from the drying experiment on the moist agglomerate without PVA, and also that the unadsorbed PVA moves with water to the surface and deposits there, the transferred amount of PVA, $M_{d}$, can be estimated by the following equation:

$$
M_{d}=\left\{\left(w_{i}-w_{c}\right) / w_{i}\right\} \times M_{a}
$$

where $M_{a}$ was assumed to be equal to the product of the mass of agglomerate and the difference between $C_{i}$ and $C_{e}$.

The observed values of the transferred amount are compared with the calculated values based on Eq. (2) in Table 1. Although the calculated values are found to be a little greater than the observed ones in the case of $C_{i}=0.94 \%$, the calculated values provide sufficient explanation for the experimental fact that the transferred amount of PVA decreases with decreasing length of the agglomerate and with decreasing $C_{i}$.

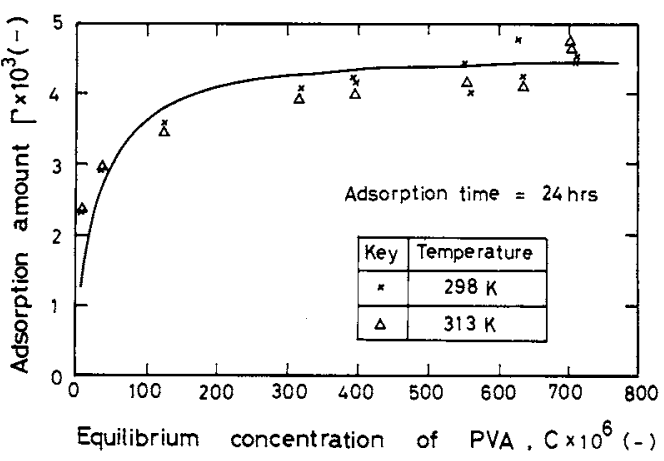

Fig. 1. Adsorption isotherm of PVA on talc particles.

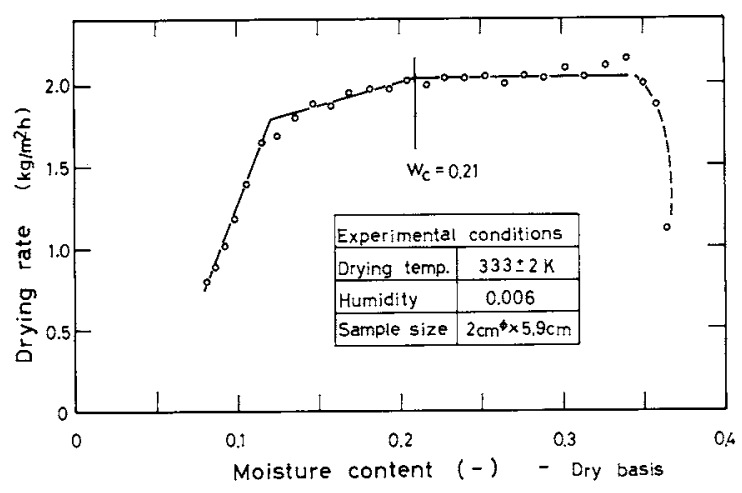

Fig. 2. Drying rate of moist agglomerate without PVA.

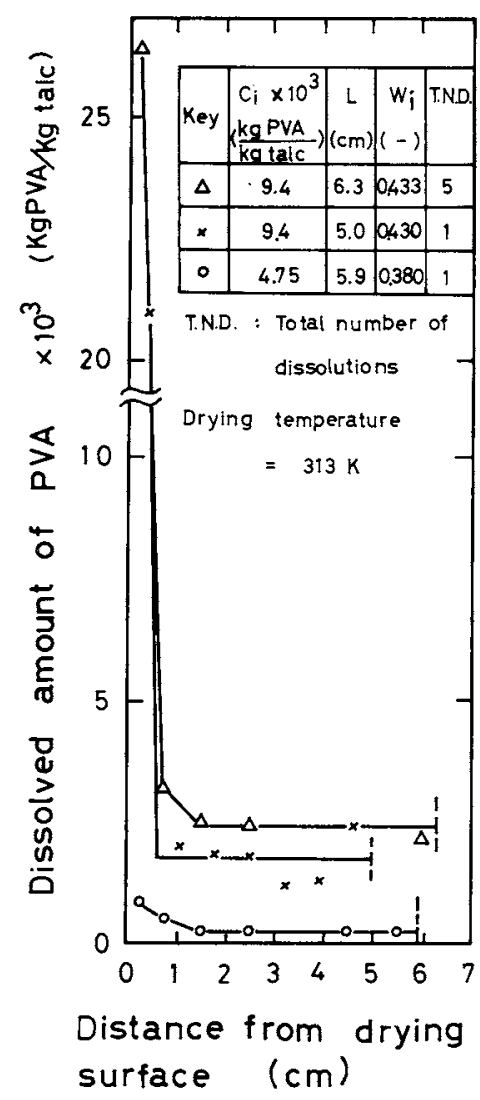

Fig. 3. Variation of dissolved amount of PVA with distance from drying surface. 
Table 1. Comparison of calculated values with experimental ones for amount of PVA transferred at and near drying surface

\begin{tabular}{lcccc}
\hline $\begin{array}{c}C_{i} \\
{[\%]}\end{array}$ & $\begin{array}{c}L \\
{[\mathrm{~cm}]}\end{array}$ & $\begin{array}{c}\text { T.N.D. } \\
{[-]}\end{array}$ & $\begin{array}{c}\text { Experimental } \\
\text { values } \times 10^{6} \\
{[\mathrm{~kg}]}\end{array}$ & $\begin{array}{c}\text { Calculated } \\
\text { values } \times 10^{6} \\
{[\mathrm{~kg}]}\end{array}$ \\
\hline 0.475 & 5.9 & 1 & 1.3 & 1.7 \\
0.94 & 5.0 & 1 & 37.3 & 45.9 \\
0.94 & 6.3 & 1 & 50.5 & 60.6 \\
0.94 & 6.3 & 5 & 51.6 & 60.6 \\
\hline
\end{tabular}

T.N.D.: Total number of dissolutions.

\section{Acknowledgment}

The author expresses his gratitude to Mr. Yoshinobu Matsuyuki of Kyushu Sankyo Co., Ltd. for his assistance in this work.

\section{Nomenclature}

C $\quad=$ concentration of PVA in solution

$[-]$
$C_{e} \quad=$ plateau adsorption value $\quad[-]$

$C_{i} \quad=$ initial additive ratio of PVA to talc

$L \quad=$ length of agglomerate $[\mathrm{m}]$

$M_{a} \quad=$ amount of PVA existing in solution among talc particles before drying $\quad[\mathrm{kg}]$

$M_{d} \quad=$ amount of PVA transferred at and near drying surface [kg]

$w_{c} \quad=$ critical moisture content $\quad[-]$

$w_{i} \quad=$ initial moisture content $\quad[-]$

$\Gamma \quad=$ adsorption amount of PVA on talc $\quad[-]$

\section{Literature Cited}

1) Kida, D.: Kobunshi, 13, 306 (1964).

2) Nakanishi, K.: Shikizai, 36, 126 (1963).

3) Pietsch, W. B.: Can. J. Chem. Eng., 47, 403 (1963).

4) van den Boomgaard, Th., T. A. King, Th. F. Tadros, H. Tang and B. Vincent: $J$. Colloid Interface Sci., 66, 68 (1978).

5) Yamada, N., H. Hirosue, H. Ihara and T. Murayama: J. Soc. Powder Tech., Japan, 20, 211 (1983).

6) Zwick, M. M.: J. Appl. Polym. Sci., 9, 2393 (1965).

\section{PERFORMANCE OF A ROTATING FLUIDIZED BED}

\author{
TERUO TAKAHASHI, ZENNOSUKE TANAKA AND AKIRA ITOSHIMA \\ Department of Industrial Chemistry, Okayama University, Okayama 700
}

L. T. FAN

Department of Chemical Engineering, Kansas State University, Manhattan, Kansas 66506, U.S.A.

Key Words: Fluidization, Fluidized Bed, Centrifugal Force, Rotating Fluidized Bed, Particle, Pressure Drop, Centrifugal Fluidization, Bed Expansion

\section{Introduction}

Centrifugal fluidization is a relatively new fluidization concept which has the advantages of higher gas flow rate, compactness, reduced particle loss by elutriation and flexibility of operation as compared with conventional fluidization. ${ }^{1)}$

It is expected that centrifugal fluidized beds (CFB's) will be applied in many fields. Works on CFB's were published by Gelperin et al. ${ }^{3)}$ and Hatch et al. ${ }^{5)}$ in 1960 . Other papers were published during the 1970's and 1980's in U.S.A., USSR, Great Britain and other countries. The majority are concerned with applications to coal combustion, gasification, classifi-

Received September 10, 1983. Correspondence concerning this article should be addressed to Z. Tanaka. A. Itoshima is now at Mitsui Engineering \& Shipbuilding Co., Ltd., Tokyo cation, food processing, and drying. It appears that relatively little effort has been spent in investigating CFB from fundamental points of view.

The present paper describes some of the experimental results obtained by the present authors by using a horizontal rotating fluidized bed with different particle densities and size distributions to determine the minimum fluidization velocity, maximum bed pressure drop, variation of pressure drop with rotating speed, and bed expansion.

\section{Experimental Apparatus and Procedure}

A sketch of the centrifugal fluidized bed and associated equipment is given in Fig. 1.

The bed rotated horizontally. The rotor was of $144 \mathrm{~mm}$ inside diameter (ID) and 10 or $20 \mathrm{~mm}$ wide. Its rotational speed ranged from 400 to 800 r.p.m. 